\title{
Evaluation of the oxygenation ratio in the definition of early graft dysfunction after lung transplantation
}

Takahiro Oto, MD, ${ }^{a}$ Bronwyn J. Levvey, RN, ${ }^{b}$ David V. Pilcher, MRCP, ${ }^{c}$ Michael J. Bailey, MSc (statistics), ${ }^{d}$ and Gregory I. Snell, FRACP

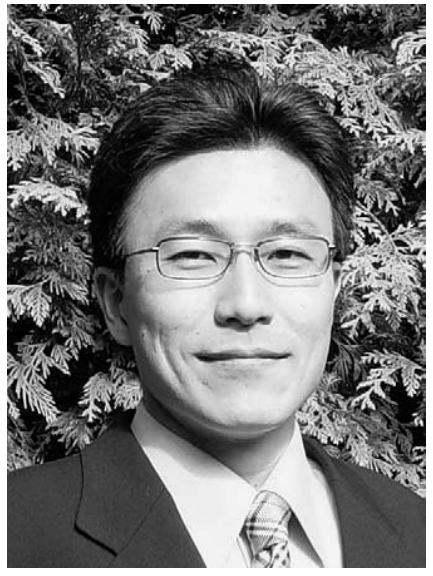

Dr Oto
Objective: Despite the clinical importance of early graft dysfunction, no standardized definition is available. We hypothesized that the arterial blood gas oxygen tension/fraction of inspired oxygen ratio $\left(\mathrm{PaO}_{2} / \mathrm{FIO}_{2}\right)$ would prove to be a useful marker for predicting subsequent outcomes of early graft dysfunction. The aims of this study were to define the prevalence of various ranges of $\mathrm{PaO}_{2} / \mathrm{FIO}_{2}$ over the first 48 hours after lung transplantation and to evaluate which measurement using the $\mathrm{PaO}_{2} / \mathrm{FiO}_{2}$ best correlates with the duration of intubation, the length of stay in the intensive care unit, and 30-day mortality, which are important alternative indicators of early graft performance.

Methods: A retrospective study was performed that included all 68 bilateral singlelung transplantations at The Alfred Hospital from January 2000 to December 2002.

Results: $\mathrm{PaO}_{2} / \mathrm{FIO}_{2}$ at 6 and 12 hours after admission to the intensive care unit was significantly associated with the duration of intubation $(r=-0.44 ; P<.001$ and $r=-0.48 ; P<.001$, respectively), and $\mathrm{PaO}_{2} / \mathrm{FIO}_{2}$ at 6 and 24 hours was also significantly associated with the length of intensive care unit stay $(r=-0.38 ; P=$ .002 and $r=-0.44 ; P=.001$, respectively). Thirty-day mortality was significantly associated with a lower $\mathrm{PaO}_{2} / \mathrm{FIO}_{2}$ at 6 hours $(219 \pm 93$ vs $306 \pm 101 ; P=.03)$.

Conclusions: $\mathrm{PaO}_{2} / \mathrm{FIO}_{2}$ taken between 6 and 12 hours after transplantation is a useful marker associated with lung transplantation outcomes. There is the potential for therapeutic interventions during this time that may be able to enhance $\mathrm{PaO}_{2} / \mathrm{FIO}_{2}$ by 12 hours and improve subsequent outcomes.

$\mathrm{L}$ ung transplantation has become an accepted therapeutic option for end-stage pulmonary disease and has resulted in remarkable overall improvements in outcome. ${ }^{1}$ However, despite advances in organ preservation, surgical techniques, Surgery, a Allergy, Immunology, and Respiratory Medicine, ${ }^{\mathrm{b}}$ Intensive Care Medicine, ${ }^{\mathrm{c}}$ and Epidemiology and Preventive Medicine, ${ }^{\mathrm{d}}$ The Alfred Hospital, Monash University, Melbourne, Victoria, Australia.

Received for publication Aug 4, 2004; revisions received Oct 13, 2004; accepted for publication Oct 28, 2004.

Address for reprints: Takahiro Oto, MD, Department of Cardiothoracic Surgery, The Alfred Hospital, Commercial Road, Melbourne, VIC 3004, Australia (E-mail: takahirooto@aol.com).

J Thorac Cardiovasc Surg 2005;130:180-6

0022-5223/\$30.00

Copyright (C) 2005 by The American Association for Thoracic Surgery

doi:10.1016/j.jtcvs.2004.10.043 and perioperative care, early mortality after lung transplantation remains notable. According to the 2003 Registry of the International Society for Heart and Lung Transplantation, $41 \%$ of 1-year deaths occur within 30 days of transplantation. Early graft dysfunction is one of the leading causes of this 30-day mortality, in turn, accounting for $30.5 \%$ of deaths in this time period. ${ }^{2}$ Early graft dysfunction encompasses other terms, such as primary graft failure, pulmonary reimplantation response, and reperfusion edema, and is clinically recognized as a impaired gas exchange, opacification of the chest radiograph, and increased pulmonary vascular resistance within 24 hours of transplantation. ${ }^{3-7}$ Whatever the original stimulus, this syndrome results in the requirement for prolonged mechanical ventilatory support with high levels of inspired oxygen and a prolonged stay in the intensive care unit (ICU). ${ }^{3-9}$

Despite the clinical importance of early graft dysfunction, no standardized definition or scoring system is available to assess its severity and to predict its outcome..$^{3-9}$ A standardized definition of early graft dysfunction enables us to grade the severity of the graft function and also to create a standardized therapeutic 
strategy for early graft dysfunction that is relevant to reducing early morbidity and mortality and their associated costs. There are also advantages for the evaluation of management strategies for donors and recipients and comparison between centers.

The arterial blood gas oxygen tension/inspired oxygen fraction ratio $\left(\mathrm{PaO}_{2} / \mathrm{FIO}_{2}\right)$ is a simple marker widely used to assess the graft function in lung transplantation ${ }^{3-9}$ and to define adult respiratory distress syndrome. ${ }^{10}$ We hypothesized that $\mathrm{PaO}_{2} /$ $\mathrm{FIO}_{2}$ would prove to be a useful marker associated with subsequent early outcomes in the definition of early graft dysfunction after lung transplantation. The aims of this study were to define the prevalence of various ranges of $\mathrm{PaO}_{2} / \mathrm{FIO}_{2}$ over the first 48 hours after lung transplantation and to evaluate which measurement using $\mathrm{PaO}_{2} / \mathrm{FIO}_{2}$ best correlates with the duration of intubation, the length of the ICU stay, and 30-day survival, which are important alternative indicators of early graft performance.

\section{Methods}

A retrospective study was performed that included all bilateral singlelung transplantation procedures at The Alfred Hospital from January 2000 to December 2002. Heart-lung and single lung transplantations were excluded from further analysis to avoid any confusion related to the variable effects of the transplanted heart on cardiac pulmonary edema or the residual native lung on hyperinflation.

\section{Transplantation Protocol}

Donor assessment, recipient selection, donor/recipient matching, surgical technique, and postoperative management proceeded according to our standard protocol, which has been described elsewhere. ${ }^{11-14}$ Although lung donor selection criteria are based on standard criteria, extended donors are commonly considered at our institution. ${ }^{15}$ In some of these cases, the donor chest radiograph may be abnormal, secretions may be purulent on bronchoscopy, and the donor $\mathrm{PaO}_{2} / \mathrm{FiO}_{2}$ may be less than $300 \mathrm{~mm} \mathrm{Hg}$.

Preoperative immunologic evaluation was routinely performed. The presence of preformed antibodies to human leukocyte antigen was screened with a panel-reactive antibody assay, and all transplant recipients were found to have values less than $10 \%$. A prospective donor/recipient $\mathrm{T}$-cell and $\mathrm{B}$-cell cross-match was performed in all cases.

Lung procurement and preservation followed standard procedures with cold-modified Euro-Collins solution for antegrade flushing. However, we infused prostacyclin (Flolan) at 40 to $80 \mathrm{ng} \cdot \mathrm{kg}^{-1}$. $\min ^{-1}$ intravenously for approximately 10 minutes before crossclamp.

Postoperative management in the ICU was performed to ensure satisfactory end-organ perfusion while maintaining a relatively low filling pressure (cardiac index, $>2.4$; pulmonary capillary wedge pressure, $<10 \mathrm{~mm} \mathrm{Hg}$; and central venous pressure, $<7 \mathrm{~mm} \mathrm{Hg}$ ). Patients with severe early graft dysfunction received a standardized evaluation and therapy with increasing complexity depending on the degree of ventilatory and hemodynamic compromise. Transesophageal echocardiography was performed to exclude lung torsion and pulmonary vascular obstruction, and a
TABLE 1. Demographics of donors and recipients

\begin{tabular}{|c|c|}
\hline Variable & Data \\
\hline \multicolumn{2}{|l|}{ Donor } \\
\hline Age, y (mean \pm SD) & $36 \pm 16$ \\
\hline $\operatorname{Sex}(F / M)$ & $32 / 36$ \\
\hline \multicolumn{2}{|l|}{ Cause of death, $\mathrm{n}(\%)$} \\
\hline Cerebral vascular accident & $35(51 \%)$ \\
\hline Trauma & $23(34 \%)$ \\
\hline Anoxic brain death & $2(3 \%)$ \\
\hline Gunshot & $4(6 \%)$ \\
\hline Other & $4(6 \%)$ \\
\hline \multicolumn{2}{|l|}{ Smoking history, $\mathrm{n}(\%)$} \\
\hline None & $28(41 \%)$ \\
\hline$<20$ pack-y & $29(43 \%)$ \\
\hline$\geq 20$ pack-y & $7(10 \%)$ \\
\hline Unknown & $4(6 \%)$ \\
\hline $\mathrm{PaO}_{2} / \mathrm{FIO}_{2}$ & $474 \pm 95$ \\
\hline \multicolumn{2}{|l|}{ Recipient } \\
\hline Age, y (mean \pm SD) & $37 \pm 14$ \\
\hline $\operatorname{Sex}(F / M)$ & $28 / 40$ \\
\hline \multicolumn{2}{|l|}{ Underlying disease, n (\%) } \\
\hline CF & $41(60 \%)$ \\
\hline COPD & $14(21 \%)$ \\
\hline ILD & $7(10 \%)$ \\
\hline $\mathrm{PH}$ & $6(9 \%)$ \\
\hline \multicolumn{2}{|l|}{ Preoperative high-risk status } \\
\hline Bipap use & $10(15 \%)$ \\
\hline Hospitalization & $13(19 \%)$ \\
\hline Cardiopulmonary bypass use & $10(15 \%)$ \\
\hline Graft ischemic time (min) & $431 \pm 135$ \\
\hline
\end{tabular}

$\mathrm{SD}$, Standard deviation; $\mathrm{PaO}_{2} / \mathrm{FlO}_{2}$, arterial blood gas oxygen tension/ fraction of inspired oxygen ratio; $C F$, cystic fibrosis; $C O P D$, chronic obstructive pulmonary disease; $I L D$, interstitial lung disease; $P H$, pulmonary hypertension; Bipap, bilevel positive airway pressure support.

retrospective cross-match was performed to exclude humoral rejection. Therapy included pressure-controlled mechanical ventilation, limitation of positive end-expiratory pressure to 12 to $15 \mathrm{~cm}$ $\mathrm{H}_{2} \mathrm{O}$, negative fluid balance with furosemide or continuous venovenous hemofiltration, inhaled nitric oxide 5 to $20 \mathrm{ppm}$, and elevation of the upper body or lateral positioning if appropriate. If these approaches failed, then extracorporeal membrane oxygenation was considered. ${ }^{14}$

Immunosuppression was based on triple therapy with cyclosporine (trough levels of 300-450 $\mu \mathrm{g} / \mathrm{L}$ ), azathioprine (1.5-2.0 $\mathrm{mg} \cdot \mathrm{kg}^{-1}$. $\left.\mathrm{d}^{-1}\right)$, and prednisolone $\left(0.15 \mathrm{mg} \cdot \mathrm{kg}^{-1} \cdot \mathrm{d}^{-1}\right)$. Prophylaxis for Pneumocystis carinii and cytomegalovirus infection was achieved with low-dose oral trimethaprim-sulfamethoxazole and intravenous ganciclovir, respectively.

\section{Data Collection}

All of the recipient data were collected from review of medical records. Best and worst $\mathrm{PaO}_{2} / \mathrm{FIO}_{2}$ within 24 and 48 hours and $\mathrm{PaO}_{2} / \mathrm{FIO}_{2}$ at $0,6,12,18,24,36$, and 48 hours after admission to the ICU were collected. When blood gas analysis data at a specific time point were not available, then the data closest to the time 


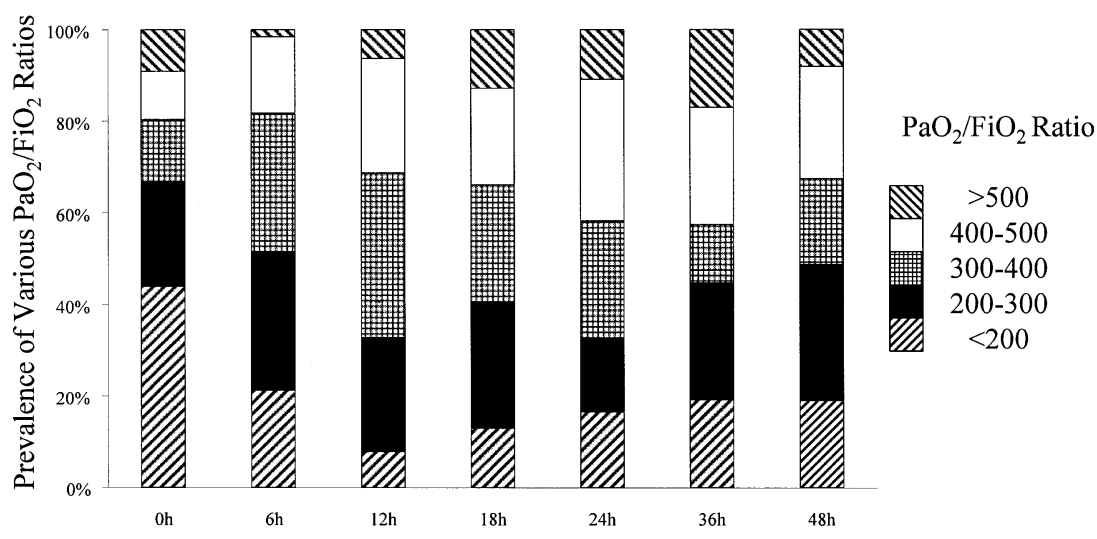

Figure 1. Prevalence of various degrees of $\mathrm{PaO}_{2} / \mathrm{FiO}_{2}$ versus time after admission to the ICU.

Time Point Following ICU Admission (hour)

point were substituted. The donor $\mathrm{PaO}_{2} / \mathrm{FIO}_{2}$ was the last arterial blood gas result on $\mathrm{FIO}_{2}=1.0$ recorded at the time of donor referral to the transplant center. The graft ischemic time of a bilateral single-lung transplantation was defined as the ischemic time for the second transplanted lungs in this study.

\section{Assessment of Outcome of Early Graft Dysfunction}

Duration of intubation, length of ICU stay, and 30-day mortality were used as outcome indicators of early graft dysfunction.

\section{Statistical Analysis}

Analysis was performed with SAS version 8.2 (SAS Institute, Inc, Cary, NC). Data were initially assessed for normality and were log-transformed where appropriate. Duration of intubation and length of ICU stay were both well approximated by a log-normal distribution. Univariate analysis was performed on log-transformed intubation time and log-transformed ICU stay by using Pearson correlation coefficients for continuous variables and Student $t$ tests for binomial variables. Multivariate analysis for these 2 outcomes was performed by using multiple linear regression. Univariate analysis for 30-day mortality was performed by using $\chi^{2}$ tests for equal proportion and logistic regression. Multivariate analysis for 30-day mortality was conducted with multiple linear regression. Time to death was further assessed by using Cox proportional hazard regression for continuous variables and log-rank tests for categorical variables. Multivariate models were constructed by using a stepwise selection technique that considered all possible prediction variables. Multivariate models were then validated with a backward-elimination technique and further assessed for biological and clinical plausibility. Continuous data were reported as mean \pm standard deviation, whereas categorical data were reported as count and proportions.

\section{Results}

From January 2000 to December 2002, a total of 68 bilateral sequential lung transplantations were performed at the Alfred Hospital, and all of these were included in this study.

\section{Donor and Recipient Demographics}

The demographics of donors and recipients are summarized in Table 1. Cerebrovascular accident $(51 \%)$ was the most
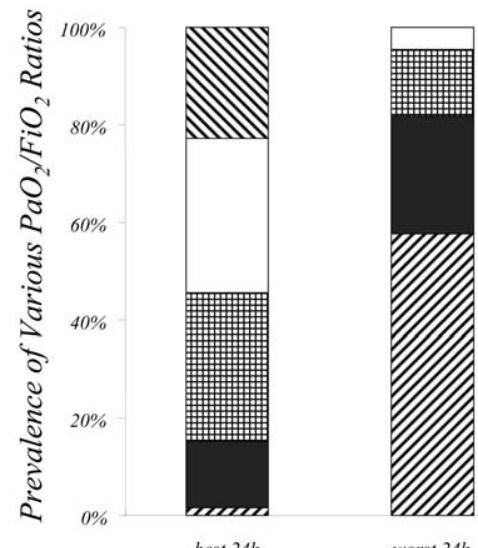

worst $24 \mathrm{~h}$

Best and Worst $\mathrm{PaO}_{2} / \mathrm{FiO}_{2}$ Ratio

In First 24 and 48 Hours Following ICU Admission
Figure 2. Best and worst $\mathrm{PaO}_{2} / \mathrm{FiO}_{2}$ in the first 24 and 48 hours after admission to the ICU. 
TABLE 2. Pearson correlation analysis for duration of intubation

\begin{tabular}{|c|c|c|c|c|}
\hline Factor & Correlation coefficient & $95 \% \mathrm{CI}$ & F value & $P$ value \\
\hline \multicolumn{5}{|l|}{$\mathrm{PaO}_{2} / \mathrm{FlO}_{2}$} \\
\hline $\mathrm{Oh}$ & -0.27 & -0.48 to -0.03 & 4.70 & .034 \\
\hline $6 \mathrm{~h}$ & -0.44 & -0.62 to -0.21 & 14.57 & $<.001$ \\
\hline $12 \mathrm{~h}$ & -0.48 & -0.65 to -0.26 & 18.00 & $<.001$ \\
\hline $18 \mathrm{~h}$ & -0.30 & -0.52 to -0.05 & 5.82 & .022 \\
\hline $24 \mathrm{~h}$ & -0.37 & -0.59 to -0.11 & 8.26 & .007 \\
\hline Best in first $24 \mathrm{~h}$ & -0.35 & -0.55 to -0.11 & 8.76 & .005 \\
\hline Worst in first $24 \mathrm{~h}$ & -0.37 & -0.56 to -0.13 & 9.70 & .003 \\
\hline \multicolumn{5}{|l|}{ Other significant factors } \\
\hline CPB use & 0.47 & 0.25 to 0.64 & 17.62 & $<.001$ \\
\hline Donor smoking history & 0.37 & 0.14 to 0.53 & 9.32 & .003 \\
\hline Donor $\mathrm{PaO}_{2} / \mathrm{FlO}_{2}$ & -0.29 & -0.49 to -0.04 & 5.68 & .022 \\
\hline
\end{tabular}

$\mathrm{PaO}_{2} / \mathrm{FlO}_{2}$, Arterial blood gas oxygen tension/fraction of inspired oxygen ratio; $\mathrm{CPB}$, cardiopulmonary bypass; $\mathrm{Cl}$, confidence interval.

common donor cause of death, followed by trauma (34\%). Ten percent of the donors had a smoking history of more than 20 pack-years. With 1 exception, all donors had a $\mathrm{PaO}_{2} / \mathrm{FIO}_{2}$ of more than 300 (mean, $474 \pm 95$ ). Most recipients had cystic fibrosis (60\%), and the percentage of interstitial lung disease and pulmonary hypertension was $10 \%$ and $9 \%$, respectively. Ten percent of the recipients had cardiopulmonary bypass during transplantation.

\section{Prevalence of $\mathrm{PaO}_{2} / \mathrm{FiO}_{2}$}

The prevalence of various ranges of $\mathrm{PaO}_{2} / \mathrm{FIO}_{2}$ at $0,6,12$, $18,24,36$, and 48 hours after admission to the ICU is depicted in Figure 1. A change in prevalence was seen from 0 to 12 hours. The prevalence of a $\mathrm{PaO}_{2} / \mathrm{FIO}_{2}$ less than 200 decreased in the range from $44 \%$ to $8 \%$, whereas the prevalence of $\mathrm{PaO}_{2} / \mathrm{FIO}_{2}$ more than 300 increased in the range from $33 \%$ to $67 \%$. After 12 hours, the prevalence of $\mathrm{PaO}_{2} /$ $\mathrm{FIO}_{2}$ seemed stable. Figure 2 shows the best and worst $\mathrm{PaO}_{2} / \mathrm{FIO}_{2}$ in the first 24 and 48 hours. $\mathrm{A} \mathrm{PaO}_{2} / \mathrm{FIO}_{2}$ more than 300 accounted for $85 \%$ of the best ratio of the first 24 hours; in contrast, it accounted for $18 \%$ of the worst ratio of the 24 hours. A similar prevalence pattern was evident if the best and worst ratios were viewed at 48 hours.

\section{Correlation Analysis Between $\mathrm{PaO}_{2} / \mathrm{FIO}_{2}$ and Duration of Intubation}

A correlation analysis of $\mathrm{PaO}_{2} / \mathrm{FIO}_{2}$ in the first 24 hours with respect to the natural log-transformed duration of intubation is summarized in Table 2. The log-transformed data were normally distributed. The $\mathrm{PaO}_{2} / \mathrm{FIO}_{2}$ at 12 hours best correlated with intubation time $(r=-0.48 ; P<.001$; Figure 3$)$, closely followed by $\mathrm{PaO}_{2} / \mathrm{FiO}_{2}$ at 6 hours $(r=-0.44 ; P<$ $.001)$.

Correlation Analysis Between $\mathrm{Pao}_{2} / \mathrm{FIO}_{2}$ and Length of ICU Stay

The $\mathrm{PaO}_{2} / \mathrm{FIO}_{2}$ at 24 hours best correlated with the natural $\log$-transformed length of ICU stay $(r=-0.44 ; P=.001)$, followed by the $\mathrm{PaO}_{2} / \mathrm{FIO}_{2}$ at 6 hours $(r=-0.38 ; P=.002)$ and 12 hours $(r=-0.36 ; P=.004$; Table 3$)$.

\section{Correlation Analysis Between $\mathrm{Pao}_{2} / \mathrm{FIO}_{2}$ and 30-Day Mortality}

Seven patients (10\%) died within 30 days after lung transplantation in this series. $\mathrm{PaO}_{2} / \mathrm{FIO}_{2}$ at 6 hours was the only significant factor related to 30-day mortality: those who died had a significantly lower $\mathrm{PaO}_{2} / \mathrm{FIO}_{2}(219 \pm 93$ vs 306 $\pm 101 ; P=.03)$.

\section{Multivariate Regression Analysis}

In the multivariate analysis, $\mathrm{PaO}_{2} / \mathrm{FiO}_{2}$ at 6 and 12 hours was the strongest predictor of duration of intubation, and $\mathrm{PaO}_{2} / \mathrm{FIO}_{2}$ at 6 and 24 hours was also the strongest predictor for length of ICU stay. All of these remained statistically significant after adjusting for any potential confounding effects.

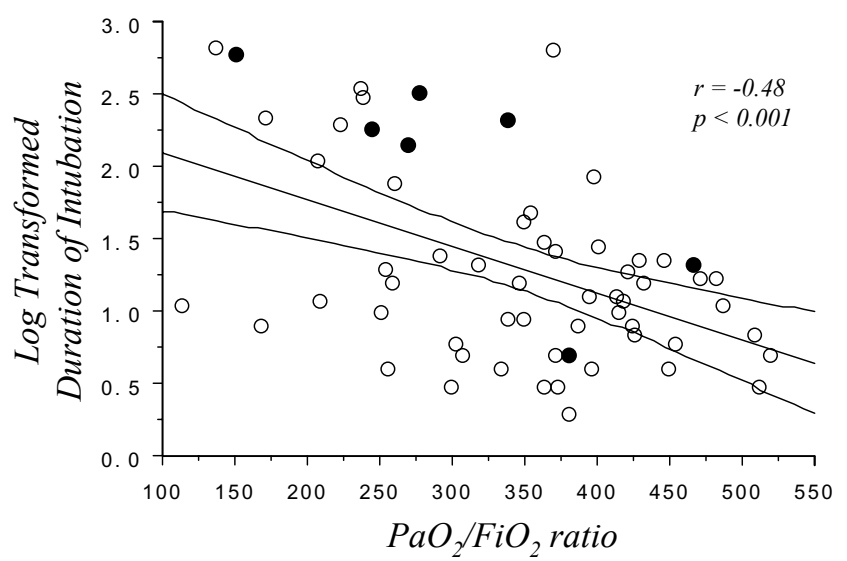

Figure 3. Correlation between log-transformed duration of intubation and $\mathrm{PaO}_{2} / \mathrm{F}_{10}$ at 12 hours after admission to the ICU (black circle indicates 30 -day death; dotted lines indicate $95 \%$ confidence interval.) 
TABLE 3. Pearson correlation analysis for length of ICU stay

\begin{tabular}{|c|c|c|c|c|}
\hline Factor & Correlation coefficient & $95 \% \mathrm{Cl}$ & $F$ value & $P$ value \\
\hline \multicolumn{5}{|l|}{$\mathrm{PaO}_{2} / \mathrm{FlO}_{2}$} \\
\hline $\mathrm{Oh}$ & -0.10 & -0.34 to 0.14 & 0.68 & .411 \\
\hline $6 \mathrm{~h}$ & -0.38 & -0.57 to -0.15 & 10.39 & .002 \\
\hline $12 \mathrm{~h}$ & -0.36 & -0.56 to -0.12 & 8.89 & .004 \\
\hline $18 \mathrm{~h}$ & -0.33 & -0.54 to -0.08 & 7.08 & .010 \\
\hline $24 \mathrm{~h}$ & -0.44 & -0.63 to -0.19 & 12.16 & .001 \\
\hline Best in first $24 \mathrm{~h}$ & -0.27 & -0.48 to -0.02 & 4.74 & .033 \\
\hline Worst in first $24 \mathrm{~h}$ & -0.33 & -0.53 to -0.09 & 7.46 & .008 \\
\hline \multicolumn{5}{|l|}{ Other significant factors } \\
\hline Donor smoking history & 0.37 & 0.14 to 0.57 & 10.17 & .003 \\
\hline CPB use & 0.36 & 0.13 to 0.55 & 9.62 & .003 \\
\hline Recipient age & 0.25 & 0.01 to 0.46 & 4.23 & .044 \\
\hline
\end{tabular}

$\mathrm{ICU}$, Intensive care unit; $\mathrm{PaO}_{2} / \mathrm{FlO}_{2}$, arterial blood gas oxygen tension/fraction of inspired oxygen ratio; $\mathrm{CPB}$, cardiopulmonary bypass; $\mathrm{Cl}$, confidence interval.

\section{Population Kaplan-Meier Analysis}

The percentage of patients not extubated versus time and the percentage of patients staying in the ICU versus time subgrouped by the degree of $\mathrm{PaO}_{2} / \mathrm{FIO}_{2}$ at 6 hours were estimated by the Kaplan-Meier method. There were significant differences between the curves of subgroups in both intubation time and ICU stay (Figure 4). Fifty-four percent of the patients with $\mathrm{PaO}_{2} / \mathrm{FIO}_{2}$ at 6 hours less than 200 remained intubated 48 hours after admission to the ICU and also remained in the ICU 7 days after transplantation.

\section{Discussion}

We have described a detailed assessment of $\mathrm{PaO}_{2} / \mathrm{FIO}_{2}$ for early graft dysfunction after lung transplantation. Different definitions of outcome of early graft dysfunction using variously classified variables, including the prevalence of prolonged mechanical ventilation and ICU stay, chest ra- diograph features, poor oxygenation results, and early mortality, have been used in published studies. ${ }^{3-9}$ Unfortunately, comparison with and between these other studies of early graft dysfunction is difficult because of the lack of a homogeneous definition. In this study, the continuous variables of duration of intubation and length of ICU stay and the categorical variable of 30-day mortality were used as alternative outcomes of early graft dysfunction to allow for comparison with all prior definitions. $\mathrm{PaO}_{2} / \mathrm{FIO}_{2}$, a simple parameter without any requirement for complicated methods in assessment and calculation, has been widely used for assessing the graft function in lung transplantation ${ }^{3-9}$ and for defining adult respiratory distress syndrome. ${ }^{10}$ Results generally match those of this study: Thabut and colleagues ${ }^{5}$ reported that the worst $\mathrm{PaO}_{2} / \mathrm{FIO}_{2}$ within the first 3 postoperative days was associated with ICU mortality, and Chatila and colleagues ${ }^{8}$ reported that the best $\mathrm{PaO}_{2} / \mathrm{FIO}_{2}$ in the first
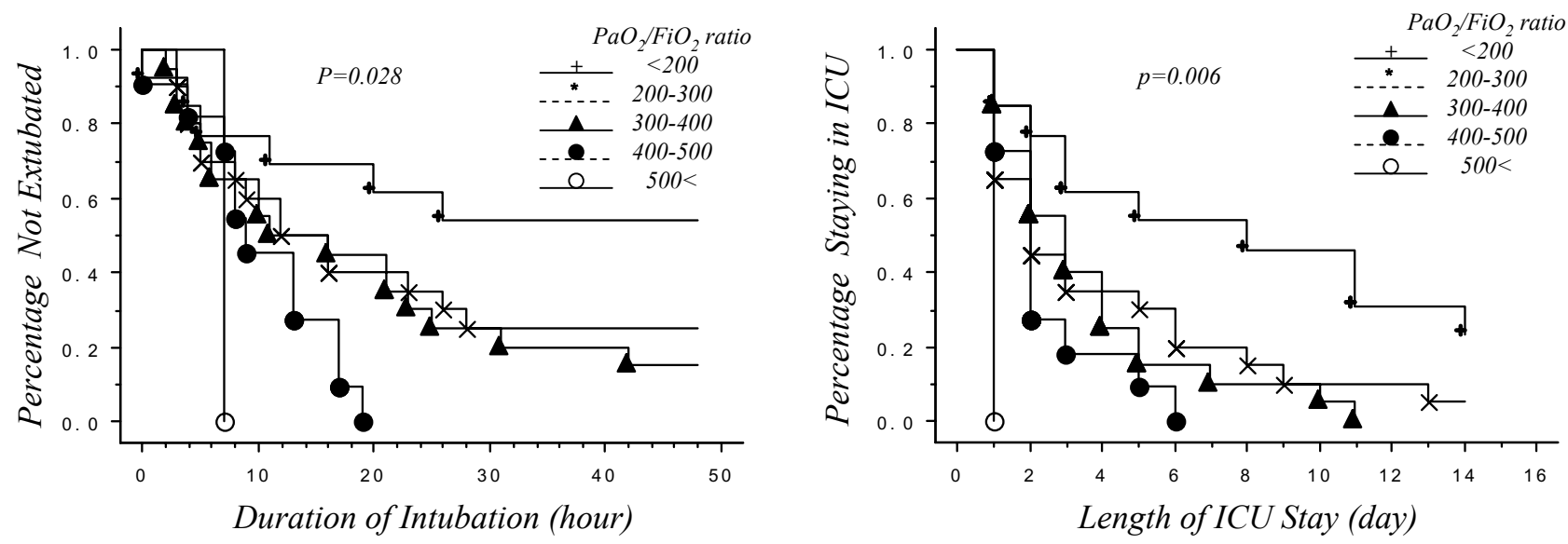

Figure 4. Percentage of patients not extubated and staying in the ICU versus time estimated by the Kaplan-Meier method. Patients were subgrouped by the degree of $\mathrm{PaO}_{2} / \mathrm{FiO}_{2}$ at 6 hours after admission to the ICU. 
24 hours was associated with prolonged mechanical ventilation. Lee and colleagues ${ }^{9}$ reported that an immediate postoperative $\mathrm{PaO}_{2} / \mathrm{FIO}_{2}$ of $<200$ correlated with an ICU stay longer than 5 days. Christie and colleagues ${ }^{4}$ included $\mathrm{PaO}_{2} / \mathrm{FIO}_{2}<200$ persisting beyond the first 48 hours in the criteria for early graft dysfunction and found it to be associated with prolonged mechanical ventilation and hospital stay.

Although $\mathrm{PaO}_{2} / \mathrm{FIO}_{2}$ has been clarified to be a predictor of early graft dysfunction, no information is available regarding which measurement using $\mathrm{PaO}_{2} / \mathrm{FIO}_{2}$ best correlates with early graft dysfunction. In this study, $\mathrm{PaO}_{2} /$ $\mathrm{FIO}_{2}$ at 6 and 12 hours after admission to the ICU was independently and strongly associated with duration of intubation, and $\mathrm{PaO}_{2} / \mathrm{FIO}_{2}$ at 6 and 24 hours was also independently and strongly associated with the length of ICU stay. $\mathrm{A} \mathrm{PaO}_{2} / \mathrm{FIO}_{2}<200$ at 6 hours seemed to indicate a prolonged duration of intubation and ICU stay (Figure 3). The $\mathrm{PaO}_{2} / \mathrm{FIO}_{2}$ at 6 hours was not significant in a final multivariate regression model for analysis of 30day mortality. It was a significant predictor in a univariate model; however, the number of actual deaths was small.

In a clinical situation, the availability of the markers using $\mathrm{PaO}_{2} / \mathrm{FIO}_{2}$ at an earlier time point (such as 6 hours) contributes to its usefulness beyond what is revealed by the data at 12 and 24 hours, because this has the potential to allow for earlier intervention for a specific group of patients with early graft dysfunction. Therefore, $\mathrm{PaO}_{2} /$ $\mathrm{FIO}_{2}$ at 6 hours might be a more useful marker than that at 12 or 24 hours.

The last donor $\mathrm{PaO}_{2} / \mathrm{FIO}_{2}$ before procurement was also a significant factor associated with the duration of intubation (Table 2). When we looked at the correlation between donor and recipient $\mathrm{PaO}_{2} / \mathrm{FIO}_{2}$, donor $\mathrm{PaO}_{2} / \mathrm{FIO}_{2}$ best correlated with recipient $\mathrm{PaO}_{2} / \mathrm{FIO}_{2}$ at 0 hours $(r=$ $0.54 ; P<.001)$. Although donor $\mathrm{PaO}_{2} / \mathrm{FIO}_{2}$ was associated with the graft oxygenation immediately after transplantation and there was a general trend toward improved graft function during the initial postoperative period up to 12 hours (Figure 1), exactly what transpires in that first 12 hours is still critical because $\mathrm{PaO}_{2} / \mathrm{FIO}_{2}$ at 12 hours proved to best correlate with the duration of intubation.

Some possible limitations to this study should be considered. First, ventilator settings potentially influenced $\mathrm{PaO}_{2} / \mathrm{FIO}_{2}$; however, postoperative ventilatory management was performed according to standard protocols, which generally aim toward the highest $\mathrm{PaO}_{2} / \mathrm{FIO}_{2}$ for minimum ventilator settings. An oxygen index [(mean airway pressure $\times$ percentage of inspired oxygen)/partial pressure of arterial oxygen] was reported to be useful for predicting early outcomes after lung transplantation ${ }^{16}$ and to be worth further investigation. However, mean airway pressure is not necessarily and easily calculated by all ventilators, is not available on extubated patients, and would not be applicable to single-lung transplantations (not addressed to this study). Second, most patients did not have a complicated postoperative course and were typically extubated on the second postoperative day. Therefore, a spectrum of severity of early graft dysfunction, ranging from a mild form that was represented only by subtle graft edema on chest radiograph to a severe form that required prolonged mechanical ventilatory support, was included in this study. It may be relevant to define only the more severe forms of early graft dysfunction. Third, we combined all causes of early graft dysfunction; however, contusion, clot, and cardiac dysfunction should possibly be removed to distinguish pure primary graft failure.

\section{Conclusion}

Graft function, simply assessable via $\mathrm{PaO}_{2} / \mathrm{FIO}_{2}$, is a constantly changing variable in the first 24 hours after lung transplantation. Any definition of early graft dysfunction (and its potential etiology and therapy) must consider this variability. Although donor $\mathrm{PaO}_{2} / \mathrm{FIO}_{2}$ best correlates with immediate graft function, subsequent traditional post-lung transplantation outcomes (duration of intubation, length of ICU stay, and 30-day survival) best correlate with $\mathrm{PaO}_{2} / \mathrm{FIO}_{2}$ 6 to 12 hours after transplantation. There is the potential for therapeutic interventions in the first 12 hours that can enhance the $\mathrm{PaO}_{2} / \mathrm{FIO}_{2}$ at 12 hours and improve subsequent outcomes.

\section{References}

1. Meyers BF, Patterson GA. Lung transplantation: current status and future prospects. World J Surg. 1999;23:1156-62.

2. Trulock EP, Edwards LB, Taylor DO, Boucek MM, Keck BM, Hertz MI. The registry of the International Society for Heart and Lung Transplantation: twenty-first official adult lung and heart-lung transplant report-2003. J Heart Lung Transplant. 2004;23:804-15.

3. Meade MO, Granton JT, Matte-Martyn A, McRae K, Weaver B, Cripps $\mathrm{P}$, et al. A randomized trial of inhaled nitric oxide to prevent ischemia-reperfusion injury after lung transplantation. Am J Respir Crit Care Med. 2003;167:1483-9.

4. Christie JD, Bavaria JE, Palevsky HI, Litzky L, Blumenthal NP, Kaiser LR, et al. Primary graft failure following lung transplantation. Chest. 1998;114:51-60.

5. Thabut G, Vinatier I, Stern JB, Lesèche G, Loirat P, Fournier M, et al. Primary graft failure following lung transplantation: predictive factors of mortality. Chest. 2002;121:1876-82.

6. de Perrot M, Liu M, Waddell TK, Keshavjee S. Ischemia-reperfusioninduced lung injury. Am J Respir Crit Care Med. 2003;167:490-511.

7. Christie JD, Kotloff RM, Pochettino A, Arcasoy SM, Rosengard BR, Landis JR, et al. Clinical risk factors for primary graft failure following lung transplantation. Chest. 2003;124:1232-41.

8. Chatila WM, Furukawa S, Gaughan JP, Criner GJ. Respiratory failure after lung transplantation. Chest. 2003;123:165-73. 
9. Lee KH, Martich GD, Boujoukos AJ, Keenan RJ, Griffith BP. Predicting ICU length of stay following single lung transplantation. Chest. 1996;110:1014-7.

10. Bernard GR, Artigas A, Brigham KL, Carlet J, Falke K, Hudson L, et al.The American-European Consensus Conference on ARDS: definitions, mechanisms, relevant outcomes, and clinical trial coordination. Am J Respir Crit Care Med. 1994;149:818-24.

11. Oto T, Griffiths A, Levvey B, Whitford H, Kotsimbos T, Rabinov M, et al. Donor history of asthma is not a contraindication to lung transplantation: 12-year single center experience. J Heart Lung Transplant. 2004;23:309-16.

12. Snell GI, Bennetts K, Bartolo J, Levvey B, Griffiths A, Williams T, et al. Body mass index as a predictor of survival in adults with cystic fibrosis referred for lung transplantation. J Heart Lung Transplant. 1998;17:1097-103.
13. Esmore DS, Brown R, Buckland M, Briganti EM, Fetherston GI, Rabinov M, et al. Techniques and results in bilateral sequential single lung transplantation. J Card Surg. 1994;9:1-14.

14. Oto T, Rosenfeldt F, Rowland M, Pick A, Rabinov M, Preovolos A, et al. Extracorporeal membrane oxygenation after lung transplantation: evolving technique improves outcomes. Ann Thorac Surg. 2004;78: 1230-5.

15. Gabbay E, Williams TJ, Griffiths AP, Macfarlane LM, Kotsimbos TC, Esmore DS, et al. Maximizing the utilization of donor organs offered for lung transplantation. Am J Respir Crit Care Med. 1999; 160:265-71.

16. Fiser SM, Kron IL, McLendon Long S, Kaza AK, Kern JA, Tribble CG. Early intervention after severe oxygenation index elevation improves survival following lung transplantation. J Heart Lung Transplant. 2001;20:631-6.

\section{Online-www.aats.org}

Now you can get The Journal of Thoracic and Cardiovascular Surgery online. The Journal online brings you faster delivery time, easy searching of current and back issues, links to PubMed, AATS, WTSA, and other important sites, and more. Visit the Journal online today.

\section{Receive tables of contents by e-mail}

To receive the tables of contents by e-mail, sign up through our Web site at http://www.mosby.com/jtcvs

Choose E-mail Notification

Simply type your e-mail address in the box and click the Subscribe button.

Alternatively, you may send an e-mail message to majordomo@mosby.com.

Leave the subject line blank and type the following as the body of your message: subscribe jtcvs_toc

You will receive an e-mail to confirm that you have been added to the mailing list.

Note that TOC e-mails will be sent out when a new issue is posted to the Web site. 